\title{
An OT Analysis of Efik Contrastive Verbal Reduplication
}

\author{
Eleanor Glewwe \\ University of California, Los Angeles
}

\section{Introduction}

This paper provides an optimality-theoretic account of Efik contrastive verbal reduplication. Efik is a Cross River language of the Benue-Congo branch of the Niger-Congo family spoken in southeastern Nigeria (Cook 1985). It is a tonal language with two level tones, high $(\mathrm{H})$ and low $(\mathrm{L})$, which may combine to form rising (LH) and falling (HL) tones (Welmers 1968). Efik also has downstepped high tones ('H). A downstepped high tone is still a high tone, not a third tone distinct from $\mathrm{H}$ or L. It only occurs after another $\mathrm{H}$, and its pitch is slightly lower than that of the preceding $\mathrm{H}$.

I begin by describing the verbal reduplication patterns to be accounted for. I then present a constraint-based analysis that derives the segments and tones of the different types of reduplicated forms. All data were elicited from a native speaker.

\section{Two Types of Contrastive Reduplication and Three Reduplication Patterns}

In VP focus constructions, Efik has two distinct types of contrastive verbal reduplication (Cook 1985) ${ }^{1}$. The first is lexical contrast reduplication, which expresses contrastive focus on the meaning of a verb:

$$
\begin{aligned}
& \text { j-'dó dwòk } \\
& \text { 3SG-LEX - throw.out } \\
& \text { 'he's throwing out (as opposed to drinking)' }
\end{aligned}
$$

In (1), reduplication serves to contrast one action with another.

The second type of contrastive verbal reduplication is performance contrast reduplication, which expresses contrastive focus on the tense/aspect properties of a verb:

$$
\begin{aligned}
& \text { ḿ-'má } \quad \text { ń-'dé } \sim \text { dép } \\
& \text { 1SG-PAST.AUX } \quad \text { 1SG-PRF buy } \\
& \text { 'I bought (already, so I don't still need to buy)' }
\end{aligned}
$$

In (2), what is being contrasted is when an action took place.

The two types of contrastive verbal reduplication give rise to three different reduplication patterns. This is because within each type of reduplication the affirmative and negative reduplicated forms differ but negative lexical contrast and negative performance contrast reduplication exhibit the same pattern.

The pattern for affirmative lexical contrast reduplication is illustrated in (3) and (4):

$$
\begin{aligned}
& \text { '́-nò njón } \\
& \text { 3SG-LEX be.tall } \\
& \text { 'he's tall' }
\end{aligned}
$$

\footnotetext{
* Many thanks to my Efik consultant, Charles Udoma, for sharing his language with me. Thanks also to Kie Zuraw and audiences at the UCLA Phonology Seminar and AMP 2016 for helpful feedback.

${ }^{1}$ In other focus constructions, the reduplication patterns are slightly different; the scope of this analysis is limited to VP focus.
} 

a. nùyó
bend.down
b. ì-kí-'nó nùyò
1PL-NEG.PAST.AUX-LEX bend.down
'bend down'
'we bent down'

In the affirmative, the lexical contrast reduplicant is a CV prefix, as shown in (3) and (4b). The C copies the first consonant of the verb root, and the $\mathrm{V}$ copies the first vowel of the verb root, except that when the verb root's vowel is [+high], the reduplicant's vowel is [-high], as in (4b). Additionally, the reduplicant exhibits tonal polarity (Yip 2002): its tone is the opposite of the (first) tone of the verb root. In (3), the verb root is high-toned, so the reduplicant is low-toned. In (4b), the first tone of the verb root is low, so the reduplicant has a high tone. Finally, under affirmative lexical contrast reduplication, a LH verb root surfaces as low-toned throughout. The verb nùyj 'bend down' has the tones LH, as shown in (4a), but under reduplication it is realized as nùyj, as in (4b).

The pattern for affirmative performance contrast reduplication is illustrated in (5) and (6):

$\begin{array}{ll}\text { ì-mà } & \text { í-'kó } \sim \text { kót } \\ \begin{array}{l}\text { 1PL-PAST.AUX } \\ \text { 'we read' }\end{array} & \text { 1PL-PRF read } \\ \text { á-'má } & \text { ó-'nó nnùyò } \\ \begin{array}{l}\text { 3SG-PAST.AUX } \\ \text { 'he bent down' }\end{array} & \text { 3SG-PRF bend.down }\end{array}$

In the affirmative, the performance contrast reduplicant is a CV prefix with the same segmental properties as the lexical contrast reduplicant. This is shown in (5) and especially in (6), which demonstrates that when the verb root's (first) vowel is [+high] the performance contrast reduplicant's vowel is also [-high]. Unlike the lexical contrast reduplicant, which exhibits a polar tone, the performance contrast reduplicant has a fixed high tone, whether the verb root's first tone is high, as in (5), or low, as in (6). Under affirmative performance contrast reduplication, a LH verb root is also realized as low-toned throughout. This can be seen again with the verb nùy'́ 'bend down,' which surfaces as nùyj̀ in (6).

In the negative, there is a single pattern for both lexical contrast and performance contrast. This pattern is illustrated in (7)-(9):

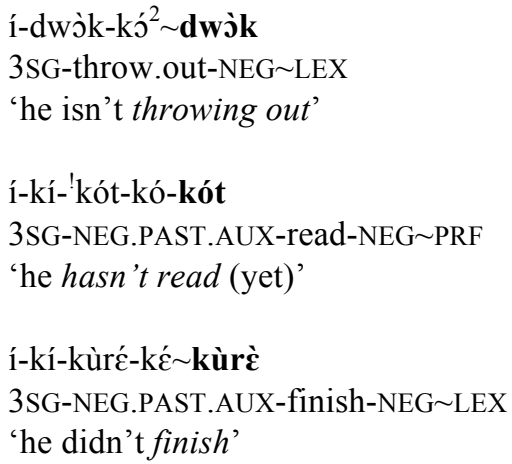

Under negation, both the lexical contrast and performance contrast reduplicants consist of a complete, non-locally suffixed copy of the verb root, including tone. In the lexical contrast example in (7), the reduplicant copies all the segmental material from the verb root $d w j k$ and is low-toned like $d w j k$. Similarly, in the performance contrast example in (8), the reduplicant copies all the segmental material from the verb root kót and is high-toned like kót. However, if the verb root is LH, like kùré 'finish' in (9), the reduplicant surfaces as low-toned throughout.

\footnotetext{
${ }^{2}$ The vowel of the negative marker $k \dot{\varepsilon}$ harmonizes with the vowel of the verb root but appears as [ع] in non-harmonizing contexts.
} 
Note that in (7)-(9), it is not possible to say with certainty which copy of the verb root is the base and which is the reduplicant. In most cases, the two copies are identical. Even in the case of kùré in (9), it is difficult to say which copy is the reduplicant. One might think that the copy with the tones LH is the base because bases tend to be more faithful than reduplicants. On the other hand, in affirmative lexical contrast and performance contrast reduplication it is the base that undergoes the change from LH to low-toned throughout, so it is possible for a base to have unfaithful tones. One piece of evidence that points toward the second copy being the reduplicant is that in non-reduplicated verb forms the negative marker $k \dot{\varepsilon}$ follows the verb root, as exemplified in (10):

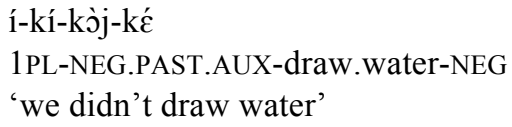

If the second copy in (9) were the base, it would be difficult to explain why the negative marker $k \dot{\varepsilon}$ precedes it when the negative marker normally follows the verb root. While this may not be a definitive means of identifying the base in negative reduplication, it seems strongly suggestive, so in (7)-(9) I have labeled the copy that precedes the negative marker the base and the copy that follows the reduplicant. In this I differ from Cook (1985), who considers all verbal reduplication prefixing, analyzes the first copy in negative reduplicated forms as the reduplicant, and claims that the negative marker metathesizes with the base.

Based on the three reduplication patterns described above, namely, affirmative lexical contrast reduplication, affirmative performance contrast reduplication, and negative lexical contrast and performance contrast reduplication, I posit three contrastive verbal reduplicants for Efik: $R_{E D} D_{L E X}, R_{P E D}$, and $\mathrm{RED}_{\mathrm{NEG}}$. The properties of these three reduplicants are summarized in Table 1.

Table 1: Properties of the three Efik contrastive verbal reduplicants

\begin{tabular}{|l|c|c|c|}
\hline & RED $_{\text {LEX }}$ & RED $_{\text {PRF }}$ & RED $_{\text {NEG }}$ \\
\hline Shape & CV prefix & CV prefix & Complete copy (suffix) \\
\hline Vowel Height & Always [-high] & Always [-high] & Faithful \\
\hline Tone(s) & Polar & High & Faithful \\
\hline Tones of LH verb & H- $\sqrt{ }$ LL & H- $\sqrt{ }$ LL & $\sqrt{L H-k \varepsilon}$-LL \\
\hline
\end{tabular}

\section{Analysis}

3.1 Segmental Analysis My analysis of Efik contrastive verbal reduplication is couched in Generalized Template Theory (McCarthy \& Prince 1995). I start by accounting for the segmental patterns, of which there are just two: affirmative lexical contrast $\left(\mathrm{RED}_{\mathrm{LEX}}\right)$ /affirmative performance contrast $\left(\mathrm{RED}_{\mathrm{PRF}}\right)$ and negative lexical/performance contrast $\left(\mathrm{RED}_{\mathrm{NEG}}\right)$. To derive the differences between $\mathrm{RED}_{\mathrm{LEX}}$ and $\mathrm{RED}_{\mathrm{PRF}}$ on the one hand and $\mathrm{RED}_{\mathrm{NEG}}$ on the other, I adopt Urbanczyk's (2006) approach, which relies on root faithfulness and the classification of reduplicants as roots or affixes. Urbanczyk discusses three different reduplicants in Lushootseed, two of which have the shape CV and one of which has the shape CVC. She argues that the CV reduplicants exhibit the properties of affixes in the language and should therefore be considered affixes while the CVC reduplicant exhibits the properties of roots and should therefore be considered a root. Here, I make the same argument about the Efik reduplicants. The negative reduplicant $\mathrm{RED}_{\mathrm{NEG}}$ shares all the characteristics of Efik roots since it is itself a complete copy of a root. Specifically, $\mathrm{RED}_{\mathrm{NEG}}$, like Efik roots, can have a complex onset or a coda consonant and can be disyllabic. $\mathrm{RED}_{\mathrm{LEX}}$ and $\mathrm{RED}_{\mathrm{PRF}}$, on the other hand, are only ever monosyllabic and cannot have complex onsets or coda consonants, making them unlike Efik roots. As far as I know, there are no non-reduplicative affixes in Efik that are longer than one syllable or have a complex onset or coda consonant, making these reduplicants resemble other affixes in the language. I therefore propose that $R_{E D} D_{L E X}$ and $R E D_{P R F}$ are affixes, subject only to general faithfulness constraints, and that $R_{E D} D_{\mathrm{NEG}}$ is a root, subject to root faithfulness constraints. 
RED $_{\text {LEX }}$ and RED PRF $_{\text {exhibit emergence-of-the-unmarked (TETU) effects that RED }}$ NEG does not: they do not have complex onsets or coda consonants, while $\mathrm{RED}_{\mathrm{NEG}}$ can. These effects are derived with the constraints in (11) and the TETU rankings in (12):

MAX-IO: Don't delete a segment from the input to the base.

MAX-BR-RoOT: Don't delete a segment from the base to a root reduplicant.

MAX-BR: Don't delete a segment from the base to a reduplicant.

*COMPLEXONSET: Don't have a complex onset in a syllable.

NoCODA: Don't have a coda in a syllable.

MAX-IO, MAX-BR-ROOT $>>$ *COMPLEXONSET, NOCODA $>>$ MAX-BR

Ranking the markedness constraints *COMPLEXONSET and NOCODA between the IO and BR-ROOT faithfulness constraints and the plain BR faithfulness constraint ensures that complex onsets and coda consonants will be preserved in non-reduplicant words and root reduplicants but not in affix reduplicants.

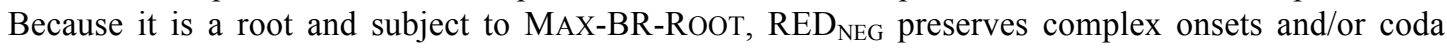
consonants present in the base, as illustrated in the tableau in (13):

\begin{tabular}{|c|c|c|c|c|c|}
\hline /dwòk-ké-RED ${ }_{\mathrm{NEG}} /$ & MAX-IO & $\begin{array}{l}\text { MAX- } \\
\text { BR-RT }\end{array}$ & *COMPONS & NoCODA & MAX-BR \\
\hline a. dwว̀k-kó-dwう̀k & & & $* *$ & $* *$ & \\
\hline b. dwòk-kó-d’̀k & & $* !$ & $*$ & $* *$ & $*$ \\
\hline c. dwòk-kó-dwう̀ & & $* !$ & $* *$ & $*$ & $*$ \\
\hline d. dwòk-kó-dذ̀ & & $* ! *$ & $*$ & $*$ & $* *$ \\
\hline e. dò-kó-dò & $* ! *$ & & & & \\
\hline
\end{tabular}

Any candidate that removes segments from the base or the root reduplicant $\mathrm{RED}_{\mathrm{NEG}}$ to avoid violating *COMPLEXONSET or NoCODA incurs fatal violations of the high-ranking faithfulness constraints, so the winner is the candidate with the fully faithful base and reduplicant.

As affixes, RED LEX $_{\text {and }}$ RED $_{\text {PRF }}$ are not subject to MAX-BR-ROOT, and since *COMPLEXONSET and NoCODA outrank MAX-BR, unmarked syllable structure emerges in these reduplicants. This is demonstrated in the tableau in (14):

\begin{tabular}{|c|c|c|c|c|c|}
\hline /RED $\mathbf{L E X}_{\text {-dwòk/ }}$ & MAX-IO & $\begin{array}{l}\text { MAX- } \\
\text { BR-RT }\end{array}$ & *COMPONS & NoCODA & MAX-BR \\
\hline a. dó-dwòk & & & * & $*$ & $* *$ \\
\hline b. dók-dwòk & & & $*$ & $* * !$ & $*$ \\
\hline c. dwó-dwòk & & & $* * !$ & $*$ & $*$ \\
\hline d. dwók-dwòk & & & $* * !$ & $* *$ & \\
\hline e. dó-dò & $* ! *$ & & & & \\
\hline
\end{tabular}

Since deleting segments from an affix reduplicant does not violate high-ranking MAX-BR-RoOT but only low-ranking MAX-BR, the candidate that best satisfies the markedness constraints wins.

RED $_{\text {LEX }}$ and RED PRF $_{\text {exhibit two more TETU effects that RED }}$ NEG does not: monosyllabicity and the lack of high vowels. The monosyllabicity of the two affix reduplicants can be derived with the constraint *STRUC- $\sigma$ and the ranking in (16):

*STRUC- $\sigma$ : Assign one violation mark for each syllable in the output.

$$
\text { MAX-IO, MAX-BR-ROOT }>>\text { *STRUC- } \sigma>>\text { MAX-BR }
$$


Because MAX-IO and MAX-BR-ROOT are ranked above *STRUC- $\sigma$, non-reduplicants and root reduplicants will preserve all their syllables, but since *STRUC- $\sigma$ outranks MAX-BR it will compel affix reduplicants to shorten.

The absence of high vowels in affix reduplicants can be derived with the following constraints and ranking:

*[+high]: A vowel should not have the feature [+high].

IDENT(high)-IO: Don't change a segment's value for the feature [high] from the input to the base. IDENT(high)-BR-ROOT: Don't change a segment's value for the feature [high] from the base to a root reduplicant.

IDENT(high)-BR: Don't change a segment's value for the feature [high] from the base to a reduplicant.

$$
\text { IDENT(high)-IO, IDENT(high)-BR-ROOT }>>*[+ \text { high }]>>\text { IDENT(high)-BR }
$$

The ranking of $*[+$ high] between IO and BR-ROOT faithfulness and plain BR faithfulness ensures that high vowels are preserved in non-reduplicants and in root reduplicants but emerge as [-high] in affix reduplicants. ${ }^{3}$

The tableau in (19) shows how $\mathrm{RED}_{\mathrm{NEG}}$, as a root, preserves the length and vowel height of the base:

\begin{tabular}{|c|c|c|c|c|c|c|c|c|}
\hline / kùré-kéc-RED & $\begin{array}{c}\text { MAX } \\
-\mathrm{IO}\end{array}$ & $\begin{array}{l}\text { MAX- } \\
\text { BR-RT }\end{array}$ & $\begin{array}{c}\text { ID(hi) } \\
\text {-IO }\end{array}$ & $\begin{array}{l}\text { ID(hi)- } \\
\text { BR-RT }\end{array}$ & $*[+$ hi $]$ & $\begin{array}{c}* \text { STRUC- } \\
\sigma\end{array}$ & $\begin{array}{c}\text { MAX- } \\
\text { BR }\end{array}$ & $\begin{array}{c}\text { ID(hi)- } \\
\text { BR }\end{array}$ \\
\hline a. kùré-ké-kùrè & & & & & $* *$ & $* * * * *$ & & \\
\hline b. kùré-ké-kòrè & & & & $* !$ & $*$ & $* * * * *$ & & $*$ \\
\hline c. kòré-k'́c-kòrè & & & $* !$ & & & $* * * * *$ & & \\
\hline d. kùré-ké-kù & & $* ! *$ & & & $* *$ & $* * * *$ & $* *$ & \\
\hline e. kùré-ké-kò & & $* ! *$ & & $*$ & * & $* * * *$ & $* *$ & $*$ \\
\hline f. kù-k'́c-kù & $* ! *$ & & & & $* *$ & $* * *$ & & \\
\hline g. kò-ké-kò & $* ! *$ & & $*$ & & & $* * *$ & & \\
\hline
\end{tabular}

Any candidate that shortens the base or the reduplicant or turns [+high] [u] into [-high] [o] to satisfy *STRUC- $\sigma$ or *[+high], respectively, violates the high-ranking IO and BR-ROOT faithfulness constraints, so $\mathrm{RED}_{\mathrm{NEG}}$ is realized with the full two syllables of the base and with the high vowel present in the base.

\begin{tabular}{|c|c|c|c|c|c|c|c|c|}
\hline /RED LEX -kùré/ & $\begin{array}{c}\text { MAX- } \\
\text { IO }\end{array}$ & $\begin{array}{l}\text { MAX- } \\
\text { BR-RT }\end{array}$ & $\begin{array}{l}\text { ID(hi)- } \\
\text { IO }\end{array}$ & $\begin{array}{l}\text { ID(hi)- } \\
\text { BR-RT }\end{array}$ & $*[+\mathrm{hi}]$ & $\begin{array}{c}* \text { STRUC- } \\
\sigma\end{array}$ & $\begin{array}{c}\text { MAX- } \\
\text { BR }\end{array}$ & $\begin{array}{l}\text { ID(hi)- } \\
\text { BR }\end{array}$ \\
\hline a. kó-kùrè & & & & & $*$ & $* * *$ & $* *$ & $*$ \\
\hline b. kóré-kùrè & & & & & $*$ & $* * * * !$ & & $*$ \\
\hline c. kú-kùrè & & & & & $* * !$ & $* * *$ & $* *$ & \\
\hline d. kúré-kùrè & & & & & $* * !$ & $* * * *$ & & \\
\hline e. kó-kòrè & & & $* !$ & & & $* * *$ & $* *$ & \\
\hline f. kó-kò & $* ! *$ & & $*$ & & & $* *$ & & \\
\hline g. kú-kù & $* ! *$ & & & & $* *$ & $* *$ & & \\
\hline
\end{tabular}

As affixes, RED LEX $_{\text {and }}$ RED $_{\text {PRF }}$ are not subject to MAX-BR-ROOT or IDENT(high)-BR-ROOT, and since $*$ STRUC- $\sigma$ outranks MAX-BR and *[+high] outranks IDENT(high)-BR, these reduplicants have as few

\footnotetext{
${ }^{3}$ The emergence of [-high] vowels as unmarked in Efik reduplicants is admittedly unusual since according to the typical markedness hierarchy high vowels are the least marked (McCarthy \& Prince 1995).
} 
syllables as possible ${ }^{4}$ and do not contain high vowels. The derivation of these properties is illustrated in the tableau in (20). Deleting syllables and changing the vowel height of the affix reduplicant in (20) does not violate the high-ranking IO and BR-ROOT faithfulness constraints, and since *[+high] and *STRUC- $\sigma$ outrank the BR faithfulness constraints, the candidate that best satisfies these two markedness constraints wins.

To sum up, the two different segmental patterns seen in Efik contrastive verbal reduplication arise because $\mathrm{RED}_{\mathrm{LEX}}$ and $\mathrm{RED}_{\mathrm{PRF}}$ are affixes and $\mathrm{RED}_{\mathrm{NEG}}$ is a root. As a root, RED $\mathrm{NEG}_{\mathrm{N}}$ is subject to BR-RoOT faithfulness constraints while the two affix reduplicants are not. Because various markedness constraints are ranked between BR-ROOT faithfulness constraints and plain BR faithfulness constraints, RED $_{\mathrm{LEX}}$ and $\mathrm{RED}_{\mathrm{PRF}}$ are CV syllables with no high vowels while $\mathrm{RED}_{\mathrm{NEG}}$ is a faithful segmental copy of the base.

3.2 Tonal Analysis Turning now to the tones of the contrastive verbal reduplicants, recall that, setting aside $\mathrm{LH}$ verb roots, $\mathrm{RED}_{\mathrm{NEG}}$ has faithful tones, $\mathrm{RED}_{\mathrm{LEX}}$ has a polar tone, and $\mathrm{RED}_{\mathrm{PRF}}$ has a fixed high tone. I first establish some faithfulness constraints for tone:

IDENT(T)-IO: A tone in the base must match the corresponding tone in the input.

IDENT(T)-BR-ROOT: A tone in a root reduplicant must match the corresponding tone in the base.

IDENT(T)-BR: A tone in a reduplicant must match the corresponding tone in the base.

*ASSOCIATE ${ }^{5}$ : For each output association line, there should be an input line such that the respective anchors of the lines correspond. (Trommer 2005)

*DissociAtE ${ }^{5}$ : For each input association line, there should be an output line such that the respective anchors of the lines correspond. (Trommer 2005)

The IDENT(T) constraints are sufficient to derive the fully faithful tones of $\mathrm{RED}_{\mathrm{NEG}}$, as illustrated in the tableau below:

\begin{tabular}{|c|c|c|c|}
\hline 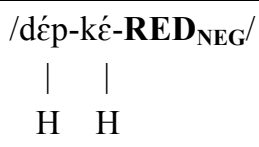 & IDENT(T)-IO & IDENT(T)-BR-RT & IDENT(T)-BR \\
\hline 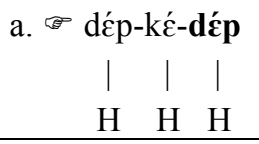 & & & \\
\hline $\begin{array}{l}\text { b. dép-ké-dèp } \\
\begin{array}{ccc}\mid & \mid & \mid \\
H & \text { H L } \\
\end{array}\end{array}$ & & $* !$ & * \\
\hline $\begin{array}{l}\text { c. dèp-ké-dèp } \\
\begin{array}{ccc}\mid & \mid & \mid \\
\text { L } & \text { H } & \text { L }\end{array}\end{array}$ & $* !$ & & \\
\hline
\end{tabular}

The candidate that preserves the original tone of the base and faithfully copies it violates no faithfulness constraints and so is the winner.

Following Anttila \& Bodomo (1996), I derive the polar tone of RED LEX with the OCP. The OCP, as defined in (23), is evaluated on the tonal tier:

OCP: Adjacent tones on the tonal tier must be different.

\footnotetext{
${ }^{4}$ High-ranking REALIZEMORPHEME prevents the affix reduplicants from being realized with zero syllables.

${ }^{5}$ Since these are faithfulness constraints, they actually come in IO, BR-ROOT, and BR versions. For this analysis, these versions do not need to be ranked differently relative to other constraints, so I bundle them here.
} 
Since non-reduplicants and $\mathrm{RED}_{\mathrm{NEG}}$ violate the OCP, as evidenced by the winner dép-ké-dép in (22), and $\mathrm{RED}_{\mathrm{LEX}}$ obeys the OCP, at the expense of tonal faithfulness, the following ranking must obtain:

$$
\text { IDENT(T)-IO, IDENT(T)-BR-ROOT }>>\text { OCP }>>\text { IDENT(T)-BR }
$$

According to this ranking, the tone of an affix reduplicant will change to satisfy the OCP, but the tones of a root reduplicant or a non-reduplicant will not.

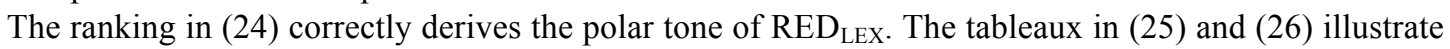
this for a high-toned verb and a low-toned verb, respectively.

\begin{tabular}{|c|c|c|c|}
\hline $\begin{array}{c}\text { RED }_{\text {LEX-njón }} / \\
\mathrm{H}\end{array}$ & IDENT(T)-IO & OCP & IDENT(T)-BR \\
\hline $\begin{array}{cc}\text { a. nò-njón } \\
\text { | } & \mid \\
\text { L } & \text { H }\end{array}$ & & & * \\
\hline b. nó-njón & & $* !$ & \\
\hline
\end{tabular}

\begin{tabular}{|c|c|c|c|}
\hline $\begin{array}{c}\text { RED }_{\text {LEX }} \text {-dwj̀k/ } \\
\mid \\
\mathrm{L}\end{array}$ & IDENT(T)-IO & OCP & IDENT(T)-BR \\
\hline 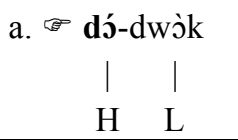 & & & * \\
\hline 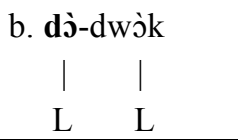 & & $* !$ & \\
\hline
\end{tabular}

The candidates in which the reduplicant has a faithful tone violate the OCP. Because the OCP is ranked above IDENT(T)-BR, these candidates lose to the candidates in which the reduplicant has an unfaithful but polar tone.

The polar tone of RED $\mathrm{LEX}_{\text {is }}$ another TETU effect. This is evident in the ranking in (24), in which a markedness constraint, here the OCP, is ranked between IO and BR-ROOT faithfulness and BR faithfulness. This polar tone is also a case of fixed segmentism (or, in this case, autosegmentism): the tone of RED LEX $_{\text {. }}$ does not match its corresponding tone in the base but is rather "fixed" as polar. Fixed segmentism, despite its name, need not mean that the segment or tone in question is always the same; in variable, or alternating, fixed segmentism, the features of the fixed segment depend on properties of the base or the wider phonological context (Alderete et al. 1999). In $\mathrm{RED}_{\mathrm{LEX}}$, the properties of the tone are fixed, but the precise realization of the tone depends on the base's tones. Alderete et al. (1999) observe that alternating fixed segmentism must always be phonological, that is, a case of the emergence of the unmarked, which I have already claimed the polar tone of $\mathrm{RED}_{\mathrm{LEX}}$ is.

Like $R D_{\mathrm{LEX}}, \mathrm{RED}_{\mathrm{PRF}}$ also exhibits fixed autosegmentism: it is invariably high-toned. If the $\mathrm{H}$ of $\mathrm{RED}_{\mathrm{PRF}}$ is another case of phonological fixed autosegmentism, it should also be a TETU effect. Such an analysis is straightforward to sketch out. If $\mathrm{H}$ emerges on $\mathrm{RED}_{\mathrm{PRF}}$ because it is unmarked, $\mathrm{H}$ must be the default tone in Efik and less marked than $\mathrm{L}$. This necessitates the ranking $* \mathrm{~L}>{ }^{*} \mathrm{H}$. The TETU ranking that will guarantee faithful tones in bases and in $\mathrm{RED}_{\mathrm{NEG}}$ but unmarked $\mathrm{H}$ in $\mathrm{RED}_{\mathrm{PRF}}$ is the following:

$$
\text { IDENT(T)-IO, IDENT(T)-BR-ROOT >> * L >> IDENT(T)-BR }
$$


This is the same TETU ranking that derives the polar tone of $\mathrm{RED}_{\mathrm{LEX}}$, except with the OCP replacing *L. Thus the markedness constraints $* \mathrm{~L}$ and the OCP are both sandwiched between IO and BR-ROOT faithfulness and BR faithfulness.

There is no complete ranking of these two TETU rankings that can account for both the polar tone of $\mathrm{RED}_{\mathrm{LEX}}$ and the fixed high tone of $\mathrm{RED}_{\mathrm{PRF}}$, however. Instead, a ranking paradox arises. ${ }^{*} \mathrm{~L}$ will induce a high tone and the OCP a polar tone on any affix reduplicant. Thus if the ranking *L $>>$ OCP obtains in the grammar, both $\mathrm{RED}_{\mathrm{LEX}}$ and $\mathrm{RED}_{\mathrm{PRF}}$ will exhibit fixed high tones, but if the ranking OCP $>$ * $\mathrm{L}$ obtains, both reduplicants will exhibit polar tones. The paradox is in fact only problematic for high-toned verb

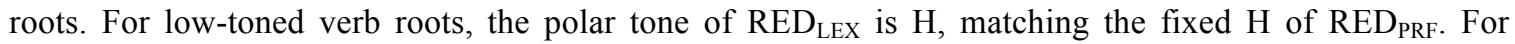

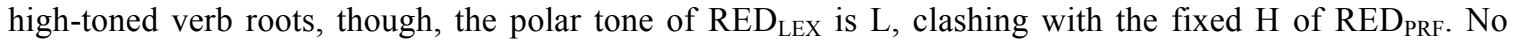
ranking of * $\mathrm{L}$ and the OCP can derive the correct tones of both affix reduplicants for high-toned verbs.

Given this paradox, the polar tone of $\mathrm{RED}_{\mathrm{LEX}}$ and the fixed high tone of $\mathrm{RED}_{\mathrm{PRF}}$ cannot both be phonological fixed autosegmentism. Because it is alternating, the polar tone of RED $\mathrm{LEX}_{\text {must }}$ be phonological fixed autosegmentism, i.e. derived with a TETU ranking. Consequently, the fixed high tone of $\mathrm{RED}_{\mathrm{PRF}}$ must fall into the second type of fixed segmentism, morphological fixed segmentism (Alderete et al. 1999). In morphological fixed segmentism, an additional affix present in the input overwrites some of the phonological material of the reduplicant. In Efik performance contrast reduplication, this affix would consist solely of a high tone, which would always accompany the performance contrast reduplicant

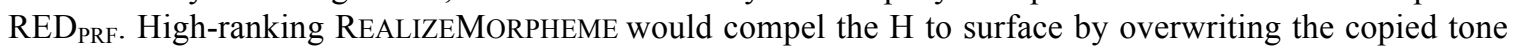

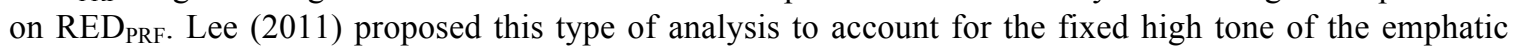
reduplicant in Thai, and I analyze the tone of the Efik RED $_{\mathrm{PRF}}$ as morphological fixed segmentism.

The tableau in (28) illustrates the derivation of the fixed high tone of RED PRF (*STRUC-T is the analogue for tone of *STRUC- $\sigma$ ):

\begin{tabular}{|c|c|c|c|c|c|c|c|}
\hline $\begin{array}{cc}\text { /Ø-RED } \\
\\
\mathrm{H} & \mathrm{H}\end{array}$ & 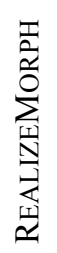 & 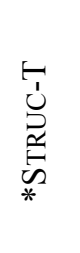 & రิ & 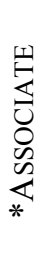 & 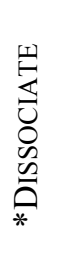 & 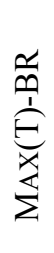 & 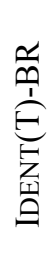 \\
\hline a. kó-kót & & $* *$ & $*$ & $*$ & & $*$ & \\
\hline $\begin{array}{c}\text { b. kó-kót } \\
/|| \\
\text { H H H }\end{array}$ & & $* * * !$ & $* *$ & $*$ & & & \\
\hline $\begin{array}{c}\text { c. kồ-kót } \\
/ \mid \\
\text { H L H }\end{array}$ & & $* * * !$ & & $*$ & & & $*$ \\
\hline \begin{tabular}{ccc} 
d. kò-kót & \multicolumn{1}{c}{$\mid$} \\
H & L & H
\end{tabular} & $* !$ & $* * *$ & & & & & $*$ \\
\hline
\end{tabular}

REALIZEMORPHEME ensures that the high tone morpheme surfaces on the reduplicant. *STRUC-T simply penalizes tones in the output. In the case of performance contrast reduplication, the tone most susceptible to deletion is the copied tone of $\mathrm{RED}_{\mathrm{PRF}}$, since the high tone morpheme is protected by REALIZEMORPHEME (and the tone of the verb root by high-ranking MAX(T)-IO). Thus the winner is the candidate in which the high tone morpheme is realized on the reduplicant and a copied tone from the base is absent. (Candidates (28a) and (28b) are homophonous, but in eliminating (28c), *STRUC-T also eliminates (28b).) The high tone of $\mathrm{RED}_{\mathrm{PRF}}$ with a low-toned verb root is derived similarly. 
The last tonal pattern that requires an account is the behavior of LH verb roots like nùy'́ 'bend down.' Recall that under affirmative lexical and performance contrast reduplication, LH verb roots become low-toned throughout, and under negative reduplication, the reduplicant (second copy) becomes low-toned throughout. Consider the examples in (29)-(31), repeated from (4), (6), and (9), respectively, along with the expected but unattested forms for the same verbs under the relevant type of reduplication:

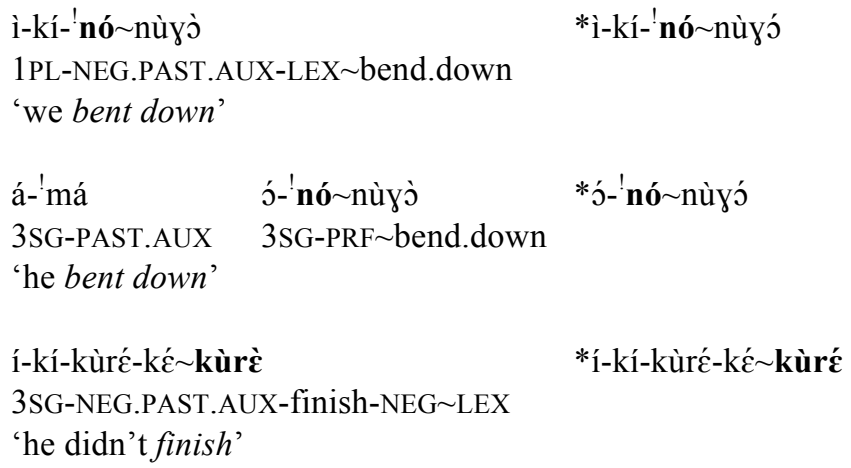

Comparing the expected but unattested forms to the attested forms, it appears that the tonal changes with LH verb roots are motivated by the desire to avoid the sequence of tones HLH. I therefore posit the constraint *HLH, which has been proposed for a variety of languages (Cahill 2007, McPherson 2016):

*HLH ${ }^{6}$ : Don't have the tonal sequence HLH, where all three tones are associated to some TBU.

There is some independent evidence for ${ }^{*} \mathrm{HLH}$ in Efik. There are seven possible surface tonal shapes for Efik disyllabic nouns: H-H, H-L, L-H, L-L, H-HL, L-HL, and H-'H. H-LH and HL-H, the shapes that would violate $* \mathrm{HLH}$, are not attested.

*HLH ensures that the verb roots in (29) and (30) and the reduplicant in (31) do not have faithful tones, but there are two ways to reassociate the underlying tones of a LH verb root to satisfy *HLH. These are shown in (33) for the verb root nùyó with an affix reduplicant:
a. nó-nùyò<smiles>C1CC2CC12</smiles>
b. nó-núyó
H L $\quad \mathrm{H}$
$\mathrm{H}$ L H

The attested forms match the configuration in (33a); that is, it is the $\mathrm{H}$ that delinks and the $\mathrm{L}$ that spreads rather than the $\mathrm{L}$ that delinks and the $\mathrm{H}$ that spreads. I ensure that the verb root (or $\mathrm{RED}_{\mathrm{NEG}}$ ) becomes low-toned and not high-toned throughout with the following constraint:

ANCHOR-L(T, M): The leftmost tone of a morpheme must be associated to the leftmost TBU of that morpheme.

ANCHOR-L(T, M) requires the $\mathrm{L}$ of a $\mathrm{LH}$ verb root to be realized because it is the leftmost tone. (33a) satisfies ANCHOR-L(T, M) while (33b) does not.

Since no reduplicated verb forms violate $*$ HLH and ANCHOR-L(T, M), they are undominated. The grammar can now derive the correct forms of LH verb roots under all three types of reduplication. The tableau in (35) shows the derivation of the surface tones of a LH verb with RED $_{\mathrm{NEG}}$. The tones of the verb root and $R_{E D} D_{N E G}$ are prevented from changing by high-ranking IDENT(T)-IO and IDENT(T)-BR-ROOT. Candidate $(35 \mathrm{c})$, in which $\mathrm{RED}_{\mathrm{NEG}}$ faithfully copies the tones of the verb root, incurs a fatal violation of

\footnotetext{
6 *HLH must operate within some circumscribed domain because surface HLH sequences are permitted in, for instance, inflected verb forms like á-sàyá 's/he is walking' and reduplicated verb forms like ć-dè-dé 's/he is sleeping.' Also, the HLH sequence ki-kùré in (31) is not repaired. The domain of *HLH must include a verb root and its reduplicant but probably not more than that.
} 
(35)

\begin{tabular}{|c|c|c|c|c|c|c|c|c|}
\hline $\begin{array}{l}\text { /kùré-ké-RED } \\
\begin{array}{lll}\mid & \mid \\
\text { L H } & \text { H }\end{array}\end{array}$ & 点 & 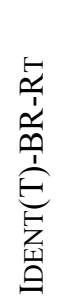 & $\begin{array}{l}\underset{*}{\mid} \\
\underset{*}{\mid}\end{array}$ & 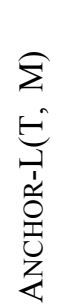 & ชิ & 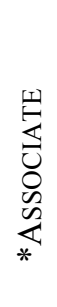 & 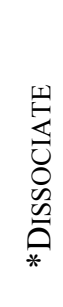 & 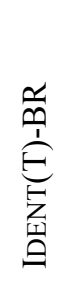 \\
\hline $\begin{array}{l}\text { a. kùré-ké-kùrè } \\
\mid \begin{array}{l}\text { | | | / } \\
\text { L H H L H }\end{array}\end{array}$ & & & & & $*$ & * & * & \\
\hline $\begin{array}{l}\text { b. kùré-ké-kúré } \\
\mid \begin{array}{c}|| \quad|| \\
\text { L H H L H }\end{array}\end{array}$ & & & & $* !$ & $*$ & $*$ & $*$ & \\
\hline $\begin{array}{l}\text { c. kùré-ké-kùré } \\
\begin{array}{ccc}\mid & \mid & \mid \\
\text { L H H } & \text { L H }\end{array}\end{array}$ & & & $* !$ & & $*$ & & & \\
\hline $\begin{array}{l}\text { d. kùré-ké-kùrè } \\
\begin{array}{cccc}\mid & \mid & \mid & \mid \\
\text { L H } & H & \text { L L } \\
\end{array}\end{array}$ & & $* !$ & & & $* *$ & & & $*$ \\
\hline $\begin{array}{l}\text { e. kùré-kè-kùré } \\
\begin{array}{cccc}\mid & \mid & \mid & \mid \\
\text { L H } & \text { L } & \text { L H } \\
\end{array}\end{array}$ & $* !$ & & & & $*$ & & & \\
\hline
\end{tabular}

(36)

\begin{tabular}{|c|c|c|c|c|c|c|c|c|}
\hline 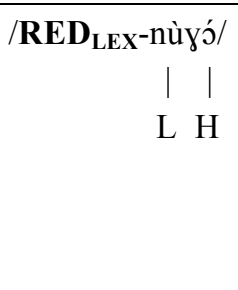 & 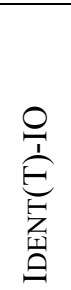 & $\underset{*}{\vec{\exists}}$ & 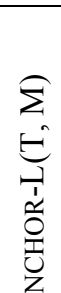 & రి & 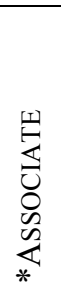 & 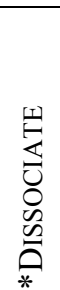 & & 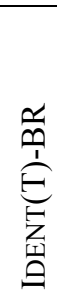 \\
\hline $\begin{array}{l}\text { a. nó-nùyò } \\
\text { | } \mid / \\
\text { H L H }\end{array}$ & & & & & $*$ & $*$ & $*$ & $*$ \\
\hline 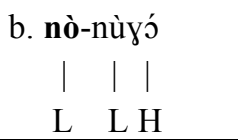 & & & & $* !$ & & & $*$ & \\
\hline $\begin{array}{c}\text { c. nó-núyó } \\
\begin{array}{ccc}\mid & \backslash \\
\text { H } & \text { L } & \text { H }\end{array}\end{array}$ & & & $* !$ & & $*$ & $*$ & $*$ & $*$ \\
\hline $\begin{array}{c}\text { d. nó-nùyó } \\
\begin{array}{ccc}\mid & \mid & \mid \\
\text { H } & \text { L H }\end{array} \\
\end{array}$ & & $* !$ & & & & & $*$ & $*$ \\
\hline $\begin{array}{l}\text { e. nó-nùyò } \\
\begin{array}{ccc}\mid & \mid & \mid \\
\text { H } & \text { L } & \text { L } \\
\end{array}\end{array}$ & $* !$ & & & $*$ & & & $*$ & $*$ \\
\hline
\end{tabular}


*HLH. ANCHOR-L(T, M) eliminates candidate (35b), in which the reduplicant is high-toned throughout, leaving the winner, in which the reduplicant is low-toned throughout.

The tableau in (36) illustrates the derivation of the surface tones of a LH verb root under affirmative lexical contrast reduplication. IDENT(T)-IO prevents the tones of the verb root from changing, and *HLH eliminates the expected output with faithful tones on the root and a polar tone on RED $\mathrm{LEX}_{\text {. }}$ ANCHOR-L(T, M) eliminates candidate (36c) in which the verb root becomes high-toned throughout instead of low-toned throughout. Making the tone of the reduplicant $\mathrm{L}$ instead of the polar $\mathrm{H}$ in candidate (36b) satisfies *HLH but violates the OCP. The winner is the candidate in which $\mathrm{RED}_{\mathrm{LEX}}$ has a polar tone and the verb root has become low-toned throughout.

Finally, the tableau below shows the derivation of the surface tones of a $\mathrm{LH}$ verb root under affirmative performance contrast reduplication:

\begin{tabular}{|c|c|c|c|c|c|c|c|c|}
\hline $\begin{array}{cc}\text { /Ø-RED } \\
\mid \\
\mathrm{H} & \mathrm{L} \text { H }\end{array}$ & 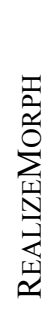 & $\underset{*}{\underset{I}{\mid}}$ & 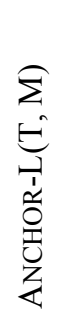 & ঠి & 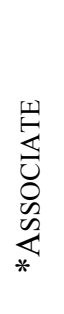 & 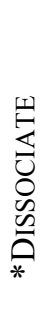 & 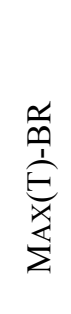 & 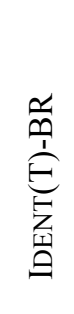 \\
\hline $\begin{array}{c}\text { a. nó-nùyj̀ } \\
/ \quad \text { | / } \\
\text { H } \quad \text { L H }\end{array}$ & & & & & $* *$ & $*$ & $* *$ & \\
\hline 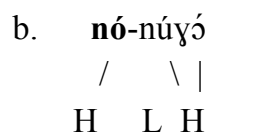 & & & $* !$ & & $* *$ & $*$ & $* *$ & \\
\hline $\begin{array}{cc}\text { c. nó-nùyó } \\
/ & \mid \\
\mathrm{H} & \mathrm{L} \\
\end{array}$ & & $* !$ & & & $*$ & & $* *$ & \\
\hline
\end{tabular}

I only include candidates in which the high tone morpheme accompanying $\mathrm{RED}_{\mathrm{PRF}}$ has been realized, satisfying REALIZEMORPHEME. The expected output, candidate (37c), incurs a fatal violation of *HLH, and ANCHOR-L(T, M) ensures that the candidate in which the verb root becomes low-toned throughout wins over the candidate in which the verb root becomes high-toned throughout.

In addition to disyllabic LH verb roots like nùyó, Efik has monosyllabic LH verb roots, such as trě 'stop.' Monosyllabic LH verb roots behave just like disyllabic ones under reduplication: the verb root becomes low-toned with $\mathrm{RED}_{\mathrm{LEX}}$ and $\mathrm{RED}_{\mathrm{PRF}}$, and the reduplicant (second copy) becomes low-toned under negative reduplication. An example with $\mathrm{RED}_{\mathrm{NEG}}$ is given in (38):

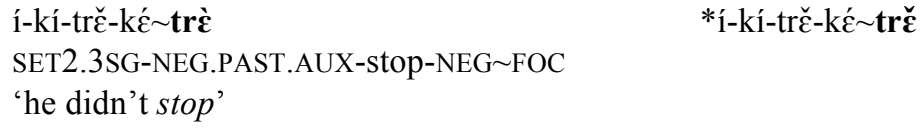

The analysis elaborated above for disyllabic LH verb roots extends straightforwardly to monosyllabic LH verb roots.

To summarize the tonal analysis, $R E D_{\mathrm{NEG}}$ has faithful tones because it is a root and therefore subject to high-ranking BR-ROOT tonal faithfulness constraints. RED $_{\text {LEX }}$ exhibits alternating phonological fixed autosegmentism: its tone is "fixed" as polar, varying depending on the tone of the base. This polar tone is derived by the OCP in a TETU ranking between IO and BR-ROOT faithfulness and BR faithfulness. Lastly, I analyze the high tone of $\mathrm{RED}_{\mathrm{PRF}}$ as morphological fixed segmentism: a morpheme consisting of a high tone always occurs with $\mathrm{RED}_{\mathrm{PRF}}$ and surfaces on the reduplicant thanks to REALIZEMORPHEME. The 
additional tonal changes seen in the reduplicated forms of LH verbs are driven by the markedness constraint *HLH.

\section{Conclusion}

I have proposed that Efik contrastive verbal reduplication makes use of three reduplicants: RED $_{\mathrm{LEX}}$ for affirmative lexical contrast reduplication, $\mathrm{RED}_{\mathrm{PRF}}$ for affirmative performance contrast reduplication, and $\mathrm{RED}_{\mathrm{NEG}}$ for both lexical and performance contrast reduplication under negation. My claim is that $\mathrm{RED}_{\mathrm{LEX}}$ and $\mathrm{RED}_{\mathrm{PRF}}$ are affixes while $\mathrm{RED}_{\mathrm{NEG}}$ is a root. I have shown that Generalized Template Theory can account for the segmental and tonal patterns exhibited by these three reduplicants. My analysis highlights some of the unusual properties of Efik contrastive verbal reduplication. The system features both alternating phonological fixed autosegmentism, arising from TETU effects, in RED $\mathrm{LEX}_{\text {and morphological }}$

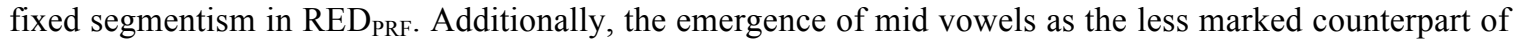
high vowels in the affix reduplicants runs counter to traditional conceptions of the markedness hierarchy in vowels.

\section{References}

Alderete, John, Jill Beckman, Laura Benua, Amalia Gnanadesikan, John McCarthy, and Suzanne Urbanczyk. (1999). Reduplication with fixed segmentism. Linguistic Inquiry, 30(3), 327-364.

Anttila, Arto and Adams Bodomo. (1996). Stress and tone in Dagaare. Ms., Stanford. ROA 169.

Cahill, Mike. (2007). More Universals of Tone. SIL Electronic Working Papers. http://www.sil.org/resources/publications/entry/7816.

Cook, T. L. (1985.) An Integrated Phonology of Efik: Volume I. Ph.D. dissertation. University of Leiden.

McCarthy, John J. and Alan S. Prince. (1995). Faithfulness and reduplicative identity. University of Massachusetts Occasional Papers in Linguistics, 18, 249-384.

McPherson, Laura. (2016). Cumulativity and ganging in the tonology of Awa suffixes. Language: Phonological Analysis, 92(1), e38-e66.

Trommer, Jochen. (2005). Polar Tone in Kanuri. Ms., University of Osnabrueck.

Urbanczyk, Suzanne. (2006). Reduplicative Form and the Root-Affix Asymmetry. Natural Language \& Linguistic Theory, 24(1), 149-240.

Welmers, Wm. E. (1968). Efik. Ibadan: Institute of African Studies, University of Ibadan.

Yip, Moira. (2002). Tone. Cambridge: Cambridge University Press. 